\title{
Enhancing Motivation Using Virtual Reality for Kindergarten Children
}

\author{
Prof\ Rabab Abdullah Abdu \\ Faculty of Science and Arts in Turaif, Saudi Arabia
}

\begin{abstract}
The current Study aims to investigate the extent of the effect of virtual reality activities on the motivation of kindergarten children. The sample consisted of 20 kindergarten children who were studied in the summer of 2019, and the research tools consisted of a skills card for virtual reality activities represented in teaching children the names of the solar system, and the colors, The methodology of the application was that the researcher made activity sessions for the children in which he introduced them to the planets of the solar system and the colors, through the virtual reality glasses that are linked to the smart phone through applications on (Google Play)( Solar Sys VR- Cyber Paint - Apps on Google Play) that the researcher presented to the children, and the results of the research came that there is a strong motivation in the children To learn and attend sessions through children's attendance of virtual reality sessions and intense focus.
\end{abstract}

Keywords: Motivation, virtual reality. Kindergarten, kindergarten children

\section{Introduction}

Historically, children were seen as things to be investigated and respected as incompetent or incomplete, yet children nowadays are seen as social actors who are "experts" in their private lives [1], [2]. This modern approach aims to systematically transfer, including a new "participatory" method of research, along with the adaptation of traditional methods, such as questionnaires and observation, which has led to the development of multimodal approaches, such as the "mosaic approach" that was developed by Clark in 1997. 2001. General methods used in research with children can be classified into two main types: visual and structured methods include some methods that can be presented in oral and non-verbal reports. Although in many studies some complementary methods may be used to obtain better results, these methods are called visual methods. Structured methods are surveys, interviews, questionnaires, and devices, while visual methods are observation, camera use, children's drawings, and avatars.

Children should be seen as participating in decision-making as adults, and in particular their right to be consulted about any decision that is made for them, and participation refers to many types of participation: social, economic, political and cultural within society as a whole and in educational terms (organization Economic Cooperation and Development (OECD 1997). In visual methods, the observation used to report specific behaviors or situations completed by researchers or parents, is particularly appropriate for conducting research with a young age [3]. With the recent availability of camera use, preschoolers have been asked to 
take pictures of things that are interesting or meaningful to them in their classroom [4]. Drawing is also a popular visual method, and it has been applied in many studies to collect information from the viewpoint of children However, many defects, such as imitation of other people's drawings, have been removed, and it may not be suitable for all children [5]. Childhood Personality focuses on both embodied and non-verbal communication practices, making meaning in places and capturing them using visual data collection techniques, Virtual reality has a lot of inclusion and benefits in many areas such as entertainment, architecture, metrology, the military, manufacturing, medicine, training, and many others [6]. He claims that virtual reality will lead to fundamental changes in the lives and activities of humans. The National Academy of Engineering has identified virtual reality as one of the fourteen major engineering challenges of the twenty-first century [7].

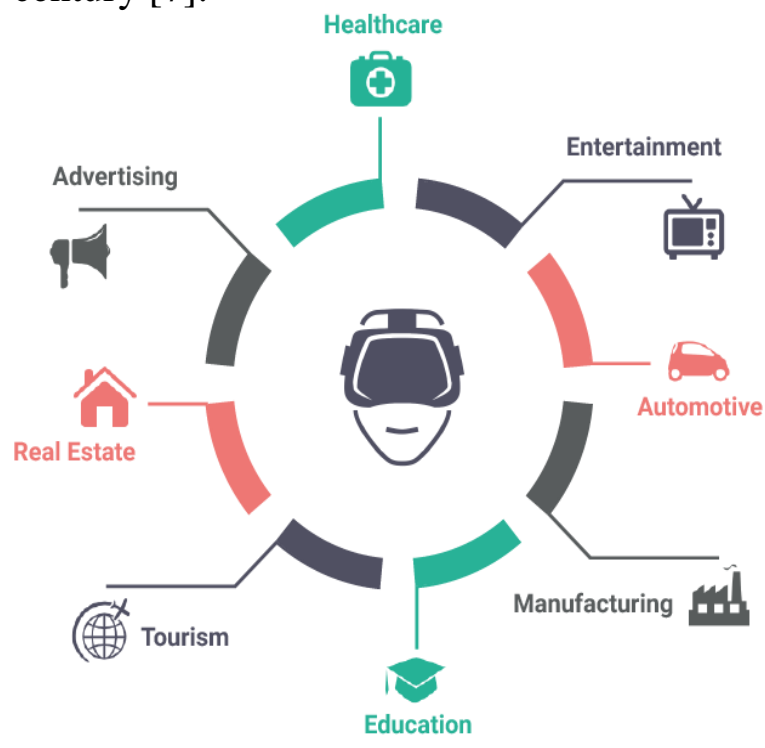

Figure (1) Virtual Reality (VR) Solutions https://www.ambitsoftware.com/digitalsolutions/virtual-reality-vr-solutions/

The understanding of virtual reality was based on the human-centered definition of Sherman and Craig who described it as a moderator composed of interactive computer simulations. This technique feels like being mentally immersed in a simulation or virtual world. A very recent definition has been introduced by Dioniso et al., Who refer to virtual reality as "computer-generated simulations of 3D objects or environments with apparently real, direct, or physical user interaction" [8].

The definition clearly confirms the three most important characteristics of virtual reality, the so-called (3I's), immersion, interaction and visualization by Burdea and Coiffet. Virtual reality is differentiated by its multiple input and output devices, which enables two-way information flow between the user and the virtual world. The virtual environment is immersive from a technological point of view if it provides stereoscopic representations of objects in real size [9].

The first example of caveman use with children was as an educational tool in the NICE project. NICE is a virtual reality system that uses CAVE to allow children to build and interact with virtual ecosystems in a way that gives them the ability to create stories according to their interaction experience [10]. The second example was a research project conducted to build an immersive virtual reality solution that improves the social and communication skills of children with autism between the ages of 9 and 12 years. The components of this VR project were developed according to pre-planned scenarios (designed based on the behaviors. Autistic people) aiming to receive a response from an autistic child using the CAVE infrastructure technique [11]. The third example is research that looks at how children and adults deal with the challenging problem of cognitive movement with implications for the real world. The study tested cycling via two paths of opposing traffic versus cycling across two paths of one-way traffic with participants; Children and adults aged 12 to 14 ride a bike simulator through an immersive virtual environment, and the results showed that children showed less skills than adults in coordinating the movement of self and things. The research has identified the implications for understanding the links between perception, action and perception and for 
identifying the risk factors underlying car and bicycle collisions [12]

\section{Virtual reality and employability}

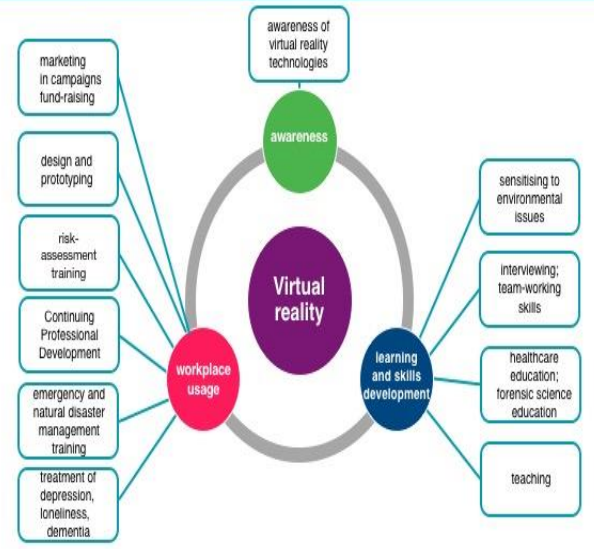

Figure (2) virtual reality technologies are being used in workplaces for learning

https://www.shaileyminocha.info/blog/2017/7/26/virtua 1-reality-for-employability-skills

\section{Methodology}

The researcher to develop the motivation of the kindergarten pupil developed some scientific concepts through the use of augmented reality by presenting a set of scientific concepts, which included (the solar system - colors) with Virtual reality technology through some smart phone applications on (Google Play) (Solar Sys VR Apps on Google Play), and the researcher designed a card to evaluate the student's performance in terms of range The student's understanding of the scientific concept from tow axes (the solar system - colors).

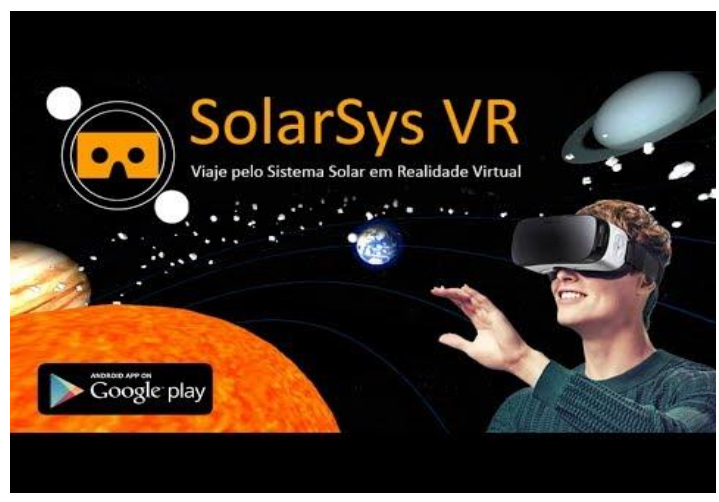

Figure (3) Solar Sys VR - Apps on Google Play

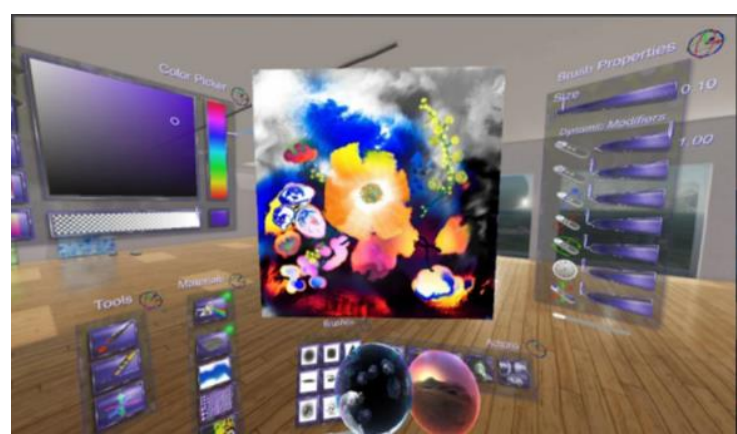

Figure (4) Cyber Paint - Apps on Google Play

The sample included (20) pupils from (2) kindergartens during the year (2019-2020), and they applied the research through (10) sessions at a rate of (2) per week, the researcher presented the concept to the student and explained it in a simple way.

\section{Results}

Using statistical methods, the value of (T-test) was calculated, as well as the means and standard deviation of the pre $\backslash$ post in the motivation skills note card during the sessions of applying the virtual reality to the definition of the solar system, and the results were in the following table(1)

Table (1) Statistical Significance for Differences Between Means of Performance Degrees for The Study Sample in motivation skills note card (Solar System)

\begin{tabular}{|l|l|l|l|l|l|l|}
\hline $\begin{array}{l}\text { solar } \\
\text { system }\end{array}$ & SD & Mean & N & FD & T & Sig \\
\hline Pre & 4.30 & 28.61 & 20 & .84 & .53 & .001 \\
\hline Post & 9.38 & 58.23 & & & & \\
\hline
\end{tabular}

And calculated, as well as the means and standard deviation of the pre $\backslash$ post in the motivation skills note card during the sessions of applying the virtual reality to the definition of the color, and the results were in the following table(2)

Table (2) Statistical Significance for Differences Between Means of Performance Degrees for The Study Sample in motivation skills note card (color)

\begin{tabular}{|l|l|l|l|l|l|l|}
\hline Color & SD & Mean & N & FD & T & Sig \\
\cline { 1 - 3 } Pre & 7.22 & 38.22 & 20 & .73 & .49 & .001 \\
\hline Post & 12.37 & 66.23 & & & & \\
\hline
\end{tabular}




\section{Discussion}

There are statistically significant differences between the average scores of pupil of the Motivation Skills Note Card during the Sessions of Applying the Virtual Reality to:-

\section{The Definition of the Solar System}

1) As a result of using virtual reality in introducing the solar system from the planets and their shapes through dedicated programs, that is why the child has a general concept of the solar system.

2) The use of virtual reality puts the child in an attractive virtual environment that helps him gain familiarity with concepts in a quick and purposeful way

3) Virtual reality helps in enhancing the child's internal motivation towards the learning process by making the scientific material more interesting and attractive

4) A preschooler needs learning based on attraction and excitement, and this is what virtual reality provides

\section{The Definition of the Color:-}

1) Kindergarten children can, through virtual reality, distinguish between colors

2) The presence of the child through the virtual reality glasses, he can live the color environment through the forms of his presence in the surrounding environment

3) Virtual reality enables children to paint in a complete virtual environment

\section{References}

[1] R.C. Moore (1986) Childhood's Domain: Play and Place in Child Development Croom Helm, London .

[2] R. Martin, C. Sexton, T. Franklin(2005) Teaching Science for all Children: An Inquiry Approach (fourth ed.), Pearson/Allyn and Bacon, Boston .

[3] Ismail Said, Nurul Nadiah Sahimi, Putri Zabariah Megat A. Rahman (2004) Revealing young children and teachers behaviour through active participation in deciding classroom layout Asia Pacific International Conference on EnvironmentBehavior Studies, Procedia - Social and Behavioral Sciences, Berlin , pp. 22-29

[4] M. Mauthner(1997) Methodological aspects of collecting data from children: lessons from three research projects J. Children Soc., 11 , pp. 16-28

[5] J. Gonya (2007), Early childhood building blocks: Turning curiosity into scientific learning, Resources for Early Childhood.

[6] W.R. Sherman,(2003) A.B. Craig Understanding Virtual Reality: Interface, Application, and Design (first ed.), Morgan Kaufmann Publishers, San Francisco .

[7] N.N. Sahimi(2010) Preschool children preferences on their school environment ASEAN Conference on EnvironmentBehavior Studies, Procardia - Social and Behavioral Sciences, Malaysia pp. 55-62.

[8] V. Morrow (2001)Using qualitative methods to elicit young people's perspectives on their environments: some ideas for community health initiatives Health Educ. Res., Theory Practice, 16 (3) (2001), pp. 255-268

[9] M. Roussos, Johnson, et al(1999).Learning and building together in an immersive virtual world Presence: Teleoperators and Virtual Environments, 8 (3), pp. 247-263,

[10] B. Williams,(2014) Bicycling across multiple lanes of one-way vs. two-way traffic, Hank Virtual Environments Lab.

[11] L. Young, H. Barrett (2001) Adapting visual methods: action research with Kampala street children Area, 33 (2), pp. 141-152.

[12] P. Häfner, V. Häfner, J. Ovtcharova (2013) Teaching methodology for virtual reality practical course. International Conference on Virtual and Augmented Reality in Education. Procedia Computer Science (2013), pp. 251-260

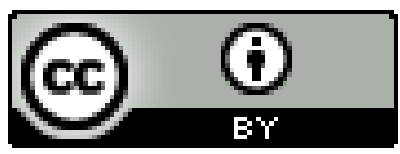

